\title{
Enhanced Wear and Corrosion in Modular Tapers in Total Hip Replacement Is Associated With the Contact Area and Surface Topography
}

\author{
Anna Panagiotidou, Jay Meswania, Jia Hua, Sarah Muirhead-Allwood, Alister Hart, Gordon Blunn \\ Institute of Orthopaedics and Musculo-Skeletal Science, University College London and the Royal National Orthopaedic Hospital, Stanmore, \\ Middlesex, HA7 4LP, United Kingdom
}

Received 25 July 2012; accepted 15 July 2013

Published online 21 August 2103 in Wiley Online Library (wileyonlinelibrary.com). DOI 10.1002/jor.22461

\begin{abstract}
Widespread concern exists about adverse tissue reactions after metal-on-metal (MoM) total hip replacement (THR). Concerns have also been expressed with wear and corrosion of taper junctions in THR. We report the effect of surface finish and contact area associated with a single combination of materials of modular tapers. In an in vitro test, we investigated the head/neck (CoCrMo/ Ti) interface of modular THRs using commercially available heads. Wear and corrosion of taper surfaces was compared following a 10 million loading cycle. Surface parameters and profiles were measured before and after testing. Electrochemical static and dynamic corrosion tests were performed under loaded and non-loaded conditions. After the load test, the surface roughness parameters on the head taper were significantly increased where the head/neck contact area was reduced. Similarly, the surface roughness parameters on the head taper were significantly increased where rough neck tapers were used. Corrosion testing showed breaching of the passive film on the rough but not the smooth neck tapers. Thus, surface area and surface finish are important factors in wear and corrosion at modular interfaces. @ 2013 Orthopaedic Research Society. Published by Wiley Periodicals, Inc. J Orthop Res 31:2032-2039, 2013
\end{abstract}

Keywords: total hip replacement; modular taper; metal on metal; corrosion; wear

Widespread concern exists about adverse tissue reactions after metal-on-metal (MoM) total hip replacement (THR). ${ }^{1-3}$ These changes are described as pseudotumors, aseptic lymphocytic vasculitis-associated lesions (ALVAL), and metallosis. ${ }^{4-6}$ Most of these adverse effects have been associated with resurfacing; however, recent reports indicate that large head MoM hip replacements (LHMoMHR) are of even greater concern. LHMoMHR was introduced to provide improved stability, increased range of motion, and reduced wear. ${ }^{1-3}$ However, the clinical outcome for LHMoMHR is uncertain. ${ }^{4}$ The 7th Annual Report of the National Joint Registry for England and Wales revealed that LHMoMHR had the highest failure rate of all hip replacement procedures. ${ }^{5}$

An important difference between MoM resurfacing and LHMoMHR is the head-trunnion modular junction, which may also include a taper sleeve adaptor. A recent report compared metal ion levels in patients with MoM resurfacing to ion levels in patients with the same bearings but with a trunnion and femoral stem and showed a three times increase in ion levels with the use of the later. ${ }^{7}$ This junction is susceptible to mechanically assisted crevice corrosion in nonMOM hips, ${ }^{8,9}$ but has only recently been investigated in retrieved LHMoMTHR systems. ${ }^{10,11}$ Langton et al. ${ }^{10}$ showed a failure rate of $25 \%$ at 6 years for the ASR resurfacing and of $48.8 \%$ for the ASR THR. Bolland et al. ${ }^{11}$ attributed failure of 17 hips to high material loss originating from the head-trunnion junction and raised the possibility that large diameter heads increase frictional torque and wear at this

Grant sponsor: Orthopaedic Research UK.

Correspondence to: Anna Panagiotidou (T: +44-0-7967581693; F: +44-0-20-84206497; E-mail: panagiotidou@btinternet.com)

(C) 2013 Orthopaedic Research Society. Published by Wiley Periodicals, Inc junction. These reports imply that wear at the trunnion is an important factor leading to high metal ion release, equivalent to wear at the articulation, which may lead to failure.

The rough surface finish on the male neck taper is the standard finish specified by some; for use with ceramic heads and is commonly used commercially. Variability exists in tolerances and surface finish of the male taper among manufacturers. Other potential factors associated with taper corrosion are the use of sleeves, sleeve composition, or the use of reduced tapers. The need to increase range of motion and prevent impingement has led manufacturers to develop shorter male tapers or partially flattened taper/ neck regions. These designs result in a reduced surface area at the junction, which may impact wear and corrosion secondary to increased stress and concentration of bending force at the interface. We investigated whether the use of neck tapers with reduced contact area resulted in enhanced wear and corrosion at the taper interface compared to standard tapers and if the surface finish of the modular components affected this.

\section{METHODS}

Neck tapers were manufactured using a conventional machine center with a constant feed rate in titanium alloy (ASTM F136-12a), and were machine finished. The neck tapers had a $12 / 14$ taper with a cone angle between $5^{\circ} 37^{\prime}$ to $5^{\circ} 42^{\prime}$. The tapers with full length taper contact were termed standard while tapers with reduced surface area were termed mini neck; they had a portion of the neck on either side reduced as two flats, which effectively reduced the contact area at the interface. All heads were $28 \mathrm{~mm}$ diameter Cobalt Chromium Molybdenum (CoCrMo) alloy from a single manufacturer with a cone angle $5^{\circ} 43^{\prime} 30^{\prime \prime}$. The heads were all +8 (long neck) to induce relatively high bending moment at the taper interface. Two tests were planned: in Test 1 , rough mini neck tapers were compared with rough standard neck 
tapers; in Test 2 rough mini neck tapers were compared with smooth mini neck tapers.

\section{Surface Parameters}

Surface profilometry was used to define the surface roughness of head and neck tapers pre and post-testing: $R_{\mathrm{a}}$ is the arithmetical mean of the absolute values of the profile deviations from the mean line; $R_{\mathrm{y}}$ is the sum of the highest peak from the mean line and the depth of the deepest valley from the mean line; and $R_{\mathrm{z}}$ value is the 10-point height of irregularities obtained from the entire evaluation length (i.e., the total of two means, the average height of the five highest peaks and the average depth of the five deepest valleys. $R_{\mathrm{a}}$, $R_{\mathrm{y}}$, and $R_{\mathrm{z}}$ values were obtained using the Mitutoyo surface roughness measuring system with Surftest SURPAK software. The surface profiles were also measured using the Taylor Hobson Talysurf 10 surface profiler. Before the tests, the head tapers had an $R_{\mathrm{a}}$ value of $0.58 \mu \mathrm{m}, R_{\mathrm{y}}$ value of $3.4 \mu \mathrm{m}$, and $R_{\mathrm{z}}$ value of $2.8 \mu \mathrm{m}$. The $R_{\mathrm{a}}$ value for the rough mini neck tapers was $2.73-2.79 \mu \mathrm{m}$, for the smooth mini neck tapers $0.28-0.38 \mu \mathrm{m}$, and for the rough standard neck tapers 2.75-3.5 $\mu \mathrm{m}$. In Test 1 measurements were made along a plane, which was the area adjacent to the non-articulating flats; in Test 2 measurements were taken along the same plane and at a plane that was $90^{\circ}$ to it.

\section{Mechanical Load Testing}

In Test 1 , rough mini neck tapers $(n=3)$ were compared with rough standard neck tapers $(n=3)$. In Test 2 , rough mini neck tapers $(n=3)$ were compared with smooth mini neck tapers $(n=3)$. Both tests were assembled in accordance with ISO7206 Part 4. The neck taper was inserted in a holderrepresenting the stem of a prosthesis with a stem/neck angle of $135^{\circ}$ and a $42 \mathrm{~mm}$ neck offset. The holders were mounted anatomically to give $10^{\circ}$ tilt in the coronal plane and $9^{\circ}$ in the sagittal plane (Fig. 1). All tests were run on a 6 station hydraulic testing machine. Throughout testing, samples were immersed in PBS solution with $\mathrm{pH}$ 7.4, aerated with air bubbles to maintain oxygen content and heated to maintain the temperature at $37^{\circ} \mathrm{C}$. The samples were sinusoidally loaded from 0.1 to $3.1 \mathrm{kN}$ for 10 million cycles at $4 \mathrm{~Hz}$.

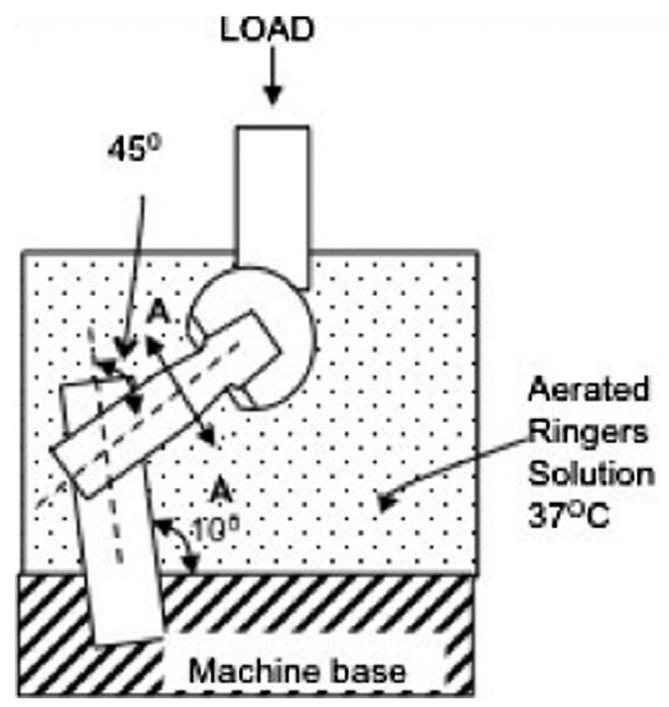

A-A

Figure 1. Diagram showing the angles of the head according to ISO 7206 Part 4: Endurance performance of stemmed femoral components with application of torsion.

\section{Electrochemical Parameters and Tests}

Two of the previously tested Test 2 components were used to examine the electro-potential of the taper interface: a rough mini neck taper $\left(R_{\mathrm{a}}=2.79 \mu \mathrm{m}\right)$ and a smooth mini neck taper $\left(R_{\mathrm{a}}=0.38 \mu \mathrm{m}\right)$. Application of electrical potential to the interface could induce additional corrosion compared with the remaining samples in both series. However, the potentiostatic test being for a relatively short time, the additional change in the surface texture was assumed negligible. The procedure involved the use of a Multistat2 computer controlled potentiostat for the measurements and control of currents and potentials including resting currents and potentials (opencircuit), potentiostatic and potentiodynamic (pitting) tests. Three types of tests can be performed with this equipment. In an open circuit potential (OCP) test, the rest values of current and potential are recorded. The rest potential is reduced if corrosion is occurring and increases again to its resting value once re-passivation is complete. In a potentiostatic test, the specimen is held at a specified potential, and the resultant current is recorded. The protective surface oxide layer acts as a semiconductor in the circuit and therefore, if it is damaged or removed, a spike in the current is observed. Lastly, in a cyclic dynamic polarization test (pitting scan), the potential is cyclically increased and decreased to specified limits. The degree of hysteresis in the potential is an indication of the specimen's affinity to undergo pitting corrosion. A Hounsfield material testing machine (Hounsfield Ltd.) was used to load the specimen during electrochemical testing. A cyclic load between 100 and 1,500 N ( $2 \times$ body weight) was used; this load is above that reported to initiate fretting corrosion in mixed alloys. ${ }^{17}$ A frequency of $0.66 \mathrm{~Hz}$ was employed. PBS at $\mathrm{pH} 7.4$ was used as the bathing solution, at room temperature $\left(20 \pm 1^{\circ}\right.$ C) in an air-conditioned temperature-controlled room. The test set-up geometry was the same as that used for the cyclic test. The OCP and current of the specimens were monitored throughout 1,000 cycles. Potentiostatic tests were carried out at a potential of $200 \mathrm{mV}$. Samples were held at this potential for $1 \mathrm{~h}$ to allow the system to regain a steady passive current before loading. Pitting scans were performed after the samples had been immersed for $1 \mathrm{~h}$ to allow a steady rest potential to be obtained. Current limits were selected with a limit of $10 \mathrm{~mA}$, with a rate of $5 \mathrm{~mA} / \mathrm{s}$ and the rate of polarization was $5 \mathrm{mV} / \mathrm{s}$. The value for a cathodic scan was $300 \mathrm{mV}$.

\section{Post-Testing Preparation and Analysis}

Damage to the taper was assessed after loading. The components were set in resin and then sectioned along the taper length using a Struers Exotom water-cooled slitting wheel to separate the head and neck without damaging the interface. The specimens were then washed in acetone in an ultrasonic bath for $1 \mathrm{~h}$ and cleaned with distilled water for $1 \mathrm{~h}$. Surface profilometry and SEMs were performed on all specimens.

\section{Statistical Analysis}

A comparison was made using a Mann-Whitney $U$-test (nonparametric) to determine any significant differences $(p=$ $<0.05$ ) between surface finishes for the mini and standard neck tapers (Test 1 ) and the rough mini and smooth mini neck tapers (Test 2).

\section{RESULTS}

\section{Surface Measurements From Test 1}

$R_{\mathrm{a}}, R_{\mathrm{y}}$, and $R_{\mathrm{z}}$ values for head tapers are summarized in Figure 2. Before the test $R_{\mathrm{a}}$ of the head tapers in 

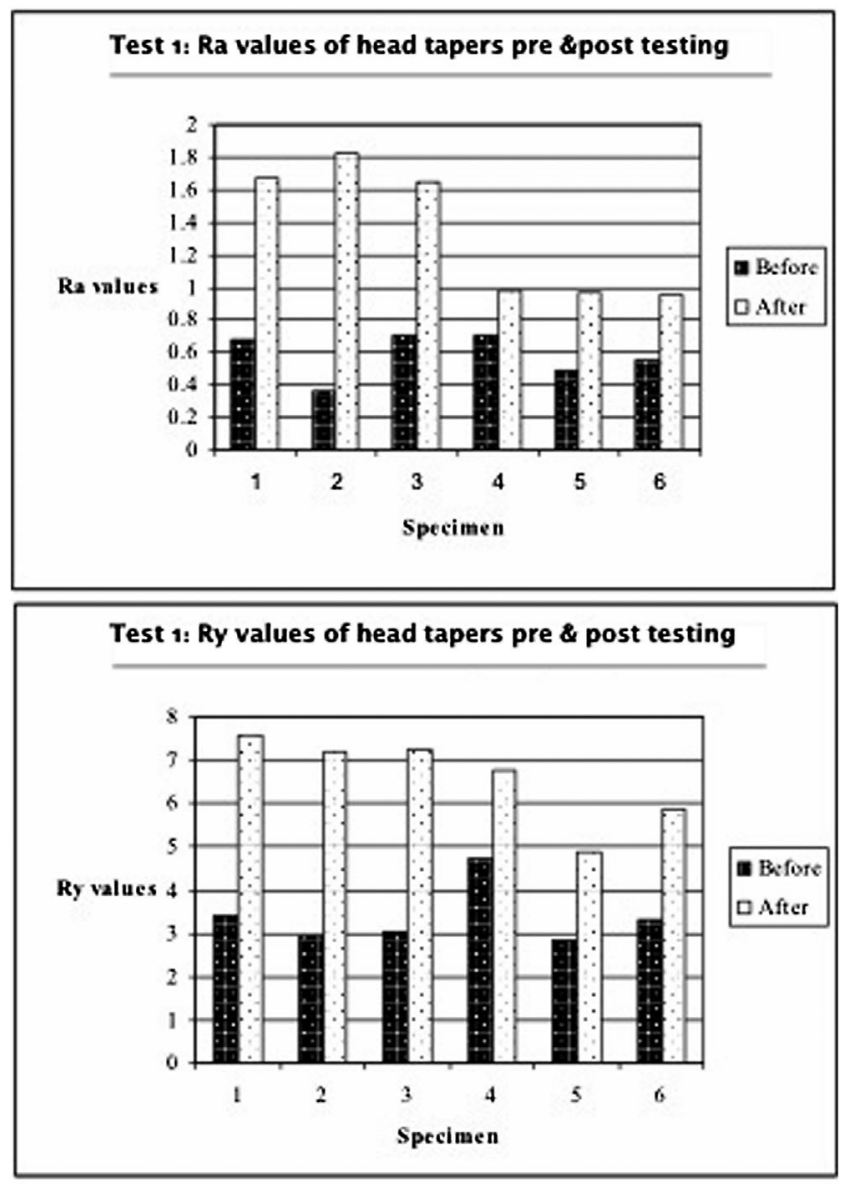

Test 1: Rz values of head tapers pre \& post testing

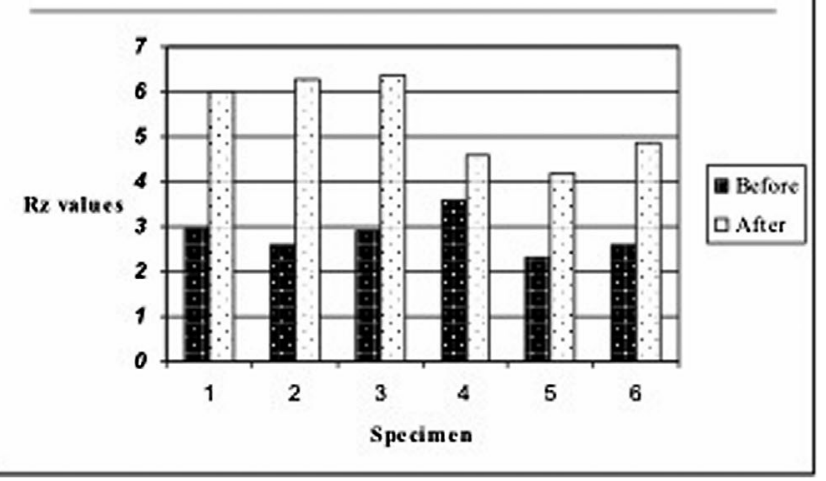

Figure 2. $R_{\mathrm{a}}, R_{\mathrm{y}}$, and $R_{\mathrm{z}}$ values for head tapers for Test 1 .

the mini and standard groups was $0.58 \mu \mathrm{m}$. After the test, the head taper $R_{\mathrm{a}}$ values in both groups increased significantly $(p=0.046)$. After cyclic loading, the mini neck taper group had higher head taper $R_{\mathrm{a}}$ values $(1.72 \mu \mathrm{m})$ compared to the standard neck taper group $(0.98 \mu \mathrm{m})$. The head taper $R_{\mathrm{y}}$ values increased in all groups after testing. The mean increase was $4.16 \mu \mathrm{m}$ in the mini group and $2.24 \mu \mathrm{m}$ in the standard group, but only the increase for the mini group was significant $(p=0.05)$. The head taper $R_{\mathrm{z}}$ increased in both groups. The increase was significant $(p=0.05)$ in the mini group where the $R_{\mathrm{z}}$ values increased from 2.9 to
$6.2 \mu \mathrm{m}$ when compared to the standard neck taper group $($ mean $=4.5 \mu \mathrm{m})$. The mean increase was $3.4 \pm 0.31 \mu \mathrm{m}$ in the mini neck taper group and $1.7 \pm 0.65 \mu \mathrm{m}$ in the standard neck taper group as compared to pre-test values. The surface profile of the head tapers changed with testing, more evidently on the heads with mini neck tapers (Fig. 3). The change in profile was most dramatic on all heads in the superior part. For heads coupled with the mini neck tapers, an area adjacent to the distal cut out remained where the original surface profile and the machine marks of the head could be identified (Fig. 4a). In the mini group, the original surface profile and machine marks on the head tapers in the inferior region (the region not in contact with the mini neck taper) could be identified in all specimens. On heads coupled with mini neck tapers, a distinct change in the surface profile occurred superiorly from the original machine marks to a surface with circumferential grooves (Fig. 4b). These grooves were more widely spaced and deeper than the original machine marks. There was loss of material with the coarser circumferential grooves, as shown by reduction in the height of the surface profile (Fig. 4c). SEM also showed that the valleys of the grooves were corroded and pitted whereas the peaks demonstrated the original machine marks (Fig. 4d).

For the neck tapers in both designs, consistency was found within the groups. $R_{\text {a }}$ values ranged from 2.73 to $2.79 \mu \mathrm{m}$ in the rough mini group and 2.75$3.5 \mu \mathrm{m}$ in the standard group. For the neck tapers, $R_{\mathrm{a}}$, $R_{\mathrm{y}}$, and $R_{\mathrm{z}}$ values showed no differences before and after testing.

\section{Surface Measurements From Test 2}

$R_{\mathrm{a}}, R_{\mathrm{y}}$, and $R_{\mathrm{z}}$ values for Test 2 for head tapers preand post-testing are shown in Figure 5. The head tapers coupled with rough mini neck tapers had an $R_{\text {a }}$ value of $0.45 \pm 0.04 \mu \mathrm{m}$. After testing, the greatest change was observed in the superior plane-(plane C$0.35 \pm 0.08 \mu \mathrm{m}$, Fig. 6). No significant change in the $R_{\text {a }}$ values occurred on head tapers with the smooth neck tapers. $R_{\mathrm{a}}$ increased for the rough tapers in plane A, but the increase was not significant; however, for this
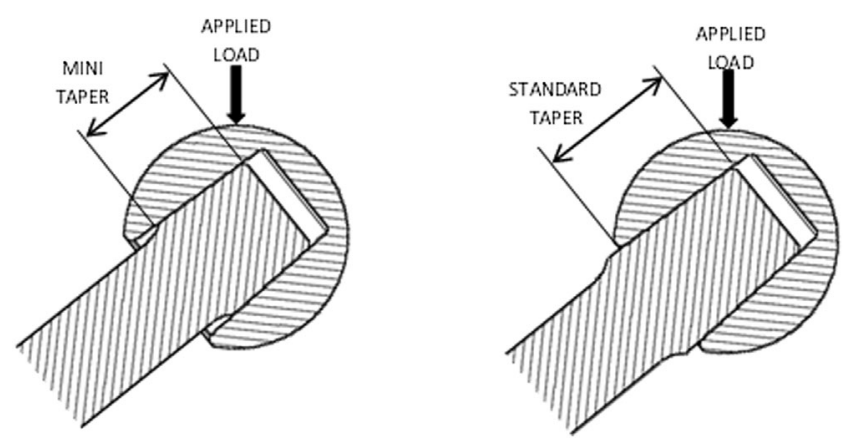

Figure 3. Diagram illustrating the difference in contact area between the mini and standard neck tapers with the head tapers. 
a

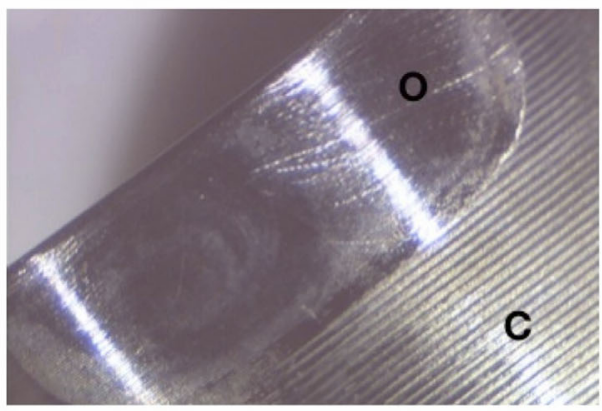

b

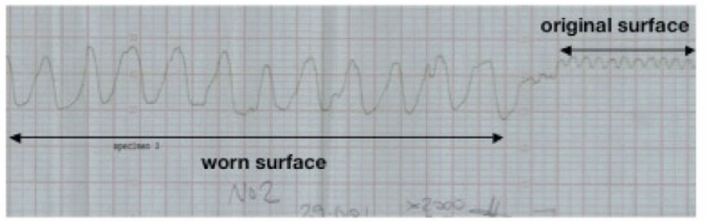

$\mathbf{C}^{-}$

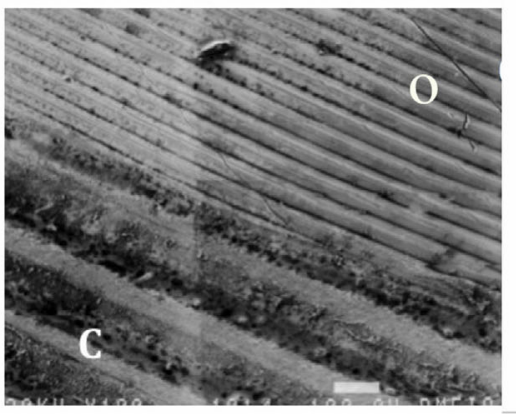

d

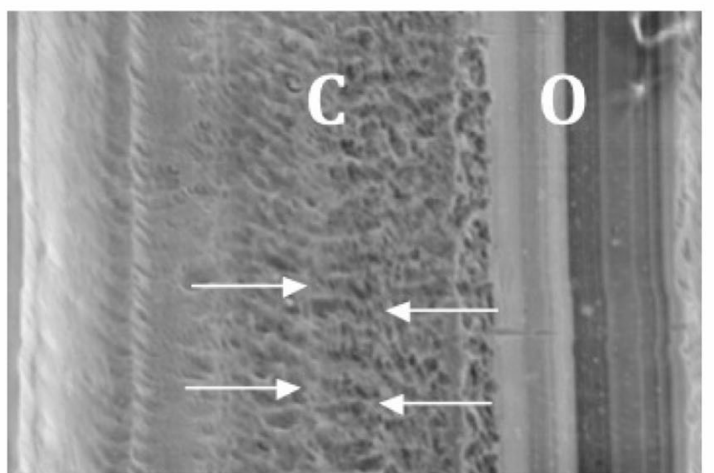

Figure 4. (a) Photograph of the internal bore of a head taper after testing showing the original surface finish $(\mathrm{O})$ and the corroded area (C). (b) Superior surface profile traces for a head taper coupled with a mini neck taper showing the original machine marks and the new circumferential marks. (c) SEM showing the original finish $(\mathrm{O})$ and broader grooves $(\mathrm{C})$ associated with loss of material. Bar $=100 \mu \mathrm{m}$. (d) SEM of the circumferential marks $(\mathrm{C})$ and the original surface finish $(\mathrm{O})$. Pitting was seen in the circumferential grooves. Marks on the peaks were seen in the corroded area (arrows) retained from the original surface.

combination, a significant increase occurred in $R_{\mathrm{a}}$ in plane C ( $p=0.04$, Fig. 6). Analysis of the head tapers coupled with smooth mini neck tapers showed an $R_{\mathrm{a}}$ of $0.22 \pm 0.04 \mu \mathrm{m}$. There was no significant change in $R_{\mathrm{a}}$ after testing along planes A and $\mathrm{C}(0.03 \pm 0.02 \mu \mathrm{m})$. When comparing $R_{\mathrm{y}}$ values (Fig. 5), significant $(p=0.05)$ increases were evident in both planes in the rough mini neck taper group, but more so in plane C. $R_{\mathrm{y}}$ was increased by $4.1 \mu \mathrm{m}$ in the rough mini neck
Test 2: Ra values pre \& post testing head tapers in planes $\hat{A} \& C$

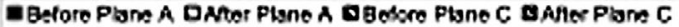

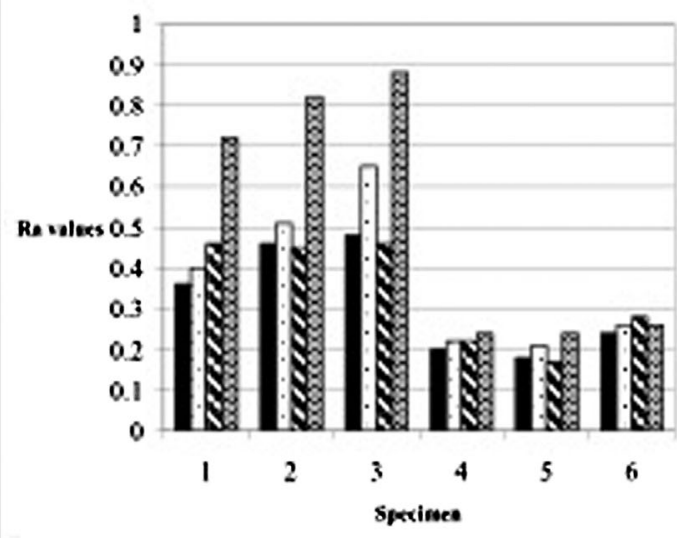

Test 2: Ry values pre \& post testing head tapers in planes $A \& C$

- Bofore Plana A Dator Flane a d Boboro Flane C Dator Flane C

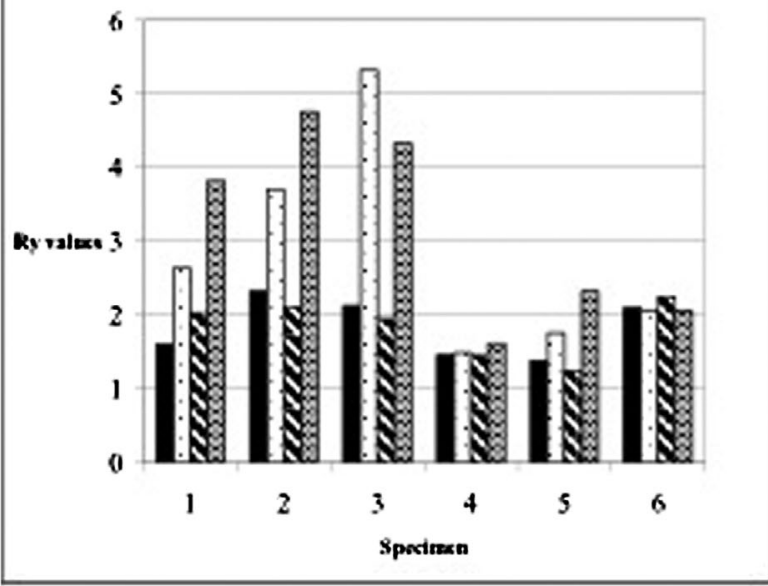

Test 2: Rx. values pre \& post testing head tapers in planes $A \& C$

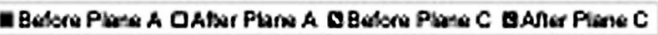

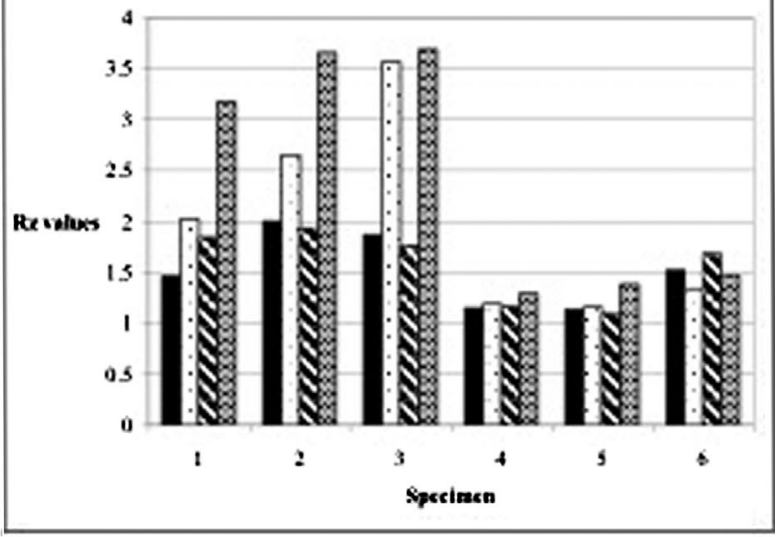

Figure 5. $R_{\mathrm{a}}, R_{\mathrm{y}}$, and $R_{\mathrm{z}}$ values for head tapers of both designs in Test 2 . Specimen 1,2 , and 3 were the rough and 4,5 , and 6 were the smooth mini neck taper groups. 


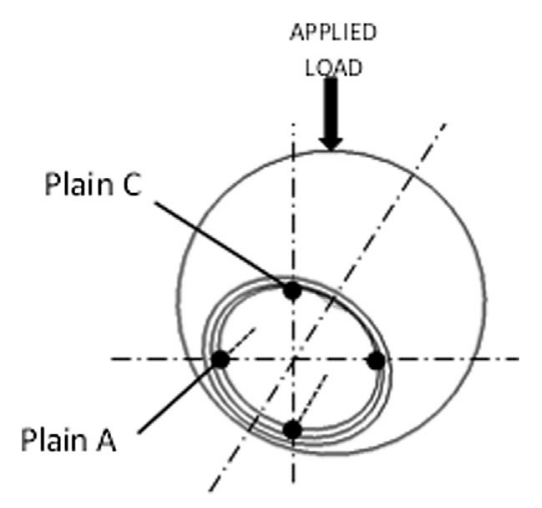

Figure 6. Diagram demonstrating plane $\mathrm{C}$ and plane A in the head tapers.

taper group, however in the smooth per group $R_{\mathrm{y}}$ was not significantly increased. Similarly, there was no significant increase for $R_{\mathrm{z}}$ for smooth mini neck taper group, but there was in $R_{\mathrm{z}}$ in the rough mini neck taper group in plane $\mathrm{C}(p=0.05)$ compared with plane A where the difference was not significant $(p=0.07)$. The surface profiles of head tapers coupled with rough mini neck tapers were similar to those in Test 1 with evidence of the original machine marks on the peaks of the coarse circumferential grooves. Debris, which could not be removed by cleaning, was evident in all smooth head tapers, with $<20 \%$ involvement of the surface area.

For the neck tapers consistency existed in both designs within the groups. $R_{\text {a }}$ ranged from 2.73 to $2.79 \mu \mathrm{m}$ in the rough group and $0.28-0.38 \mu \mathrm{m}$ in the smooth group. For the neck tapers, $R_{\mathrm{a}}, R_{\mathrm{y}}$, and $R_{\mathrm{z}}$ values showed no difference before and after testing. All male tapers showed negligible corrosive damage.

\section{Electrochemical Measurements}

A notable difference was found between the two finishes when monitoring the OCP of the mini neck tapers before and during loading. The difference was significant $(p \leq 0.05)$ after 1,000 cycles. The OCP on the rough mini neck taper decreased by $158 \pm 11.5 \mathrm{mV}$ compared to $11 \pm 3.5 \mathrm{mV}$, indicating that the oxide film on the rough taper was being ruptured. The smooth taper in comparison showed little change. Potentiostatic tests showed an immediate spike in current as loading started on the rough taper, which continued to fluctuate with cyclic load (Fig. 7a). Loading had no noticeable effect on current for the smooth taper. The current for the rough taper generally decreased throughout loading until near the end of the test, indicating that the initial damage was greater but the rough taper surface could repassivate to some degree. The current decreased with each loading cycle, indicating a decrease in the damage caused by fretting the longer the rough taper was loaded. To assess the effect of a low data acquisition rate, loading regimes of 10 cycles were applied at different speeds, and the current was plotted against the induced load. The current increased when load was applied and decreased as the load diminished (Fig. 7b). Currents were notably larger at the higher loading showing the frequency dependence of fretting. Pitting scans showed a change with loading on both mini neck tapers; however, the change was more evident in the rough taper where a hysteresis loop was seen (Fig. 8). A lower potential was required for the current to diminish on the rough taper. This difference was marginal, but provided evidence that the crevice environment for the rough taper had become worse than with the smooth taper and over a longer period of time an enlarged loop may be observed.

\section{DISCUSSION}

Modularity is a central design feature of THR implants and is utilized by most manufacturers. Corrosion in the crevice that is formed at the modular junction between the two component parts is a concern. ${ }^{12}$ This connection typically consists of a metalmetal or a ceramic-metal conical junction with a tapered femoral trunnion that couples with a head that has a tapered bore. These tapers vary commercially in surface roughness, materials, cone diameter and angles, tolerances, and the surface area of the articulation, and all these factors have an important role in implant performance. ${ }^{13-16}$

In Test 1, the surface profile of the heads with both types of neck tapers showed a significant change with testing, indicating that material from the CoCrMo surface adjacent to the titanium alloy neck tapers had "eroded" and the surface texture of the neck taper had in fact imprinted onto the head taper. This imprinting indicates that the original smooth surface of the head taper was changed to a more roughened surface while the surface finish of the neck taper remained unchanged. This was related to the loading, and the changes were most evident on the superior part of the head taper, which was the region of greatest bending forces. Bolland et al. ${ }^{8}$ reported this morphological change with black markings and deposits on the head taper modular interface in retrieved implants, and although we were able to reproduce the surface texture in our in vitro 10 million-cycle test, we did not see any material deposition. We also observed this phenomenon in retrieved heads from large MoM THRs. The original surface can be clearly identified on these heads, and the circumferential grooves approximate the morphology of the neck taper surface (Fig. 9). We also believe that these changes may be associated with the high torque placed on large heads. We did not simulate torque, but we have noted that the circumferential pattern was accentuated by reducing the surface contact area of the neck taper and by using a rough surface finish, which is used for many THRs and may be generating higher stresses, especially those created by fictional torque in large heads.

Although surface topology shows significant material loss, it was difficult to accurately calculate the 
$\underline{a}$
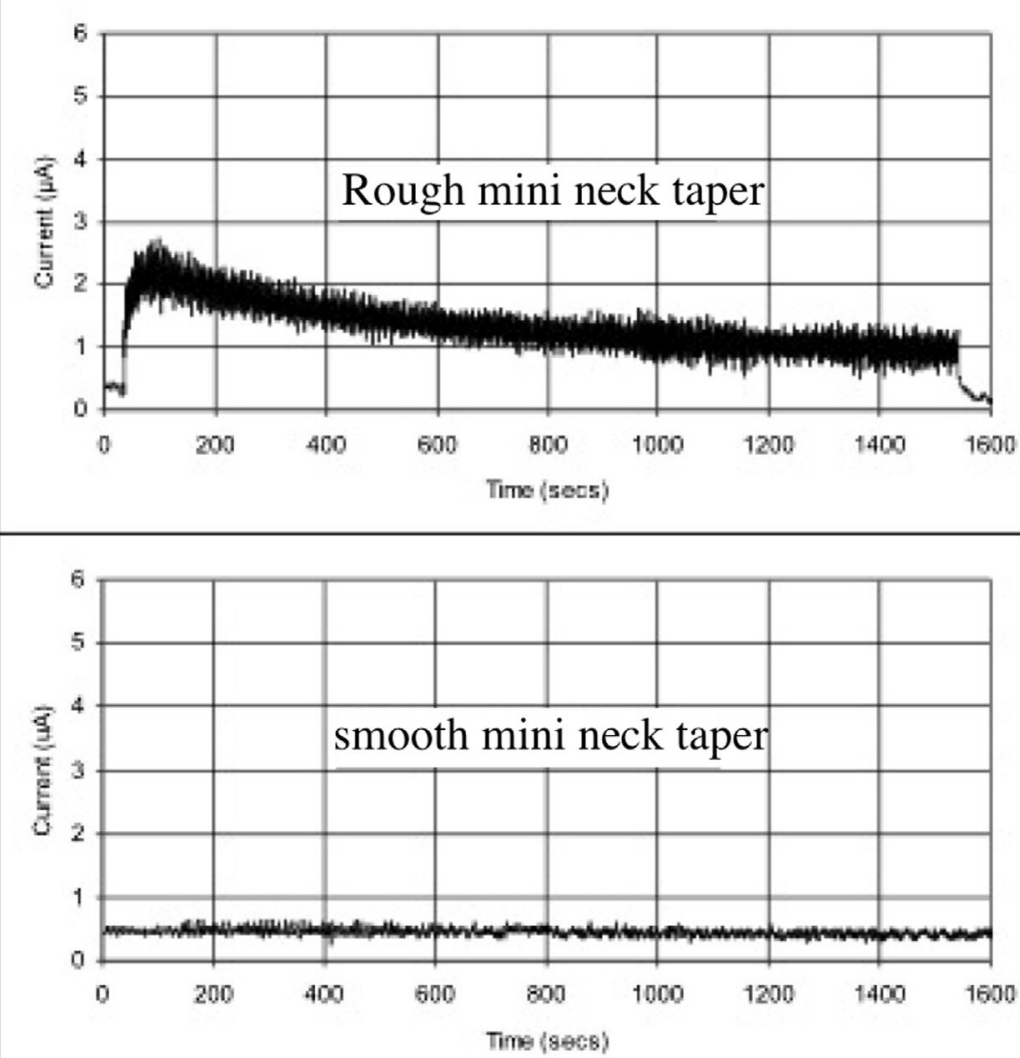

b

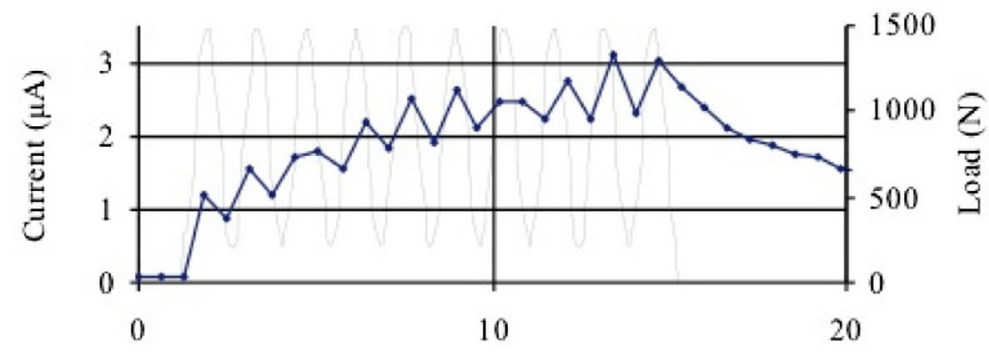

Time (secs)

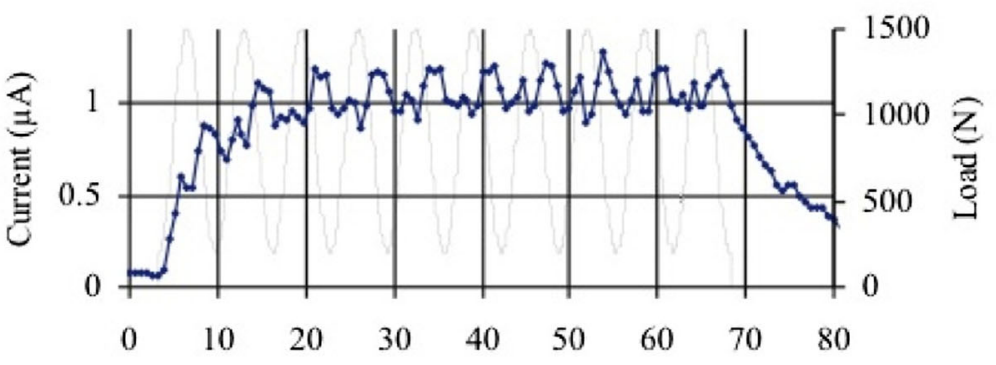

Time (secs)

Current Load

Figure 7. (a) Potentiostatic tests-current response of loading at applied potential of $200 \mathrm{mV}$ during loading at $0.66 \mathrm{~Hz}$. (b) Current and load plots on a mini neck taper for 10 cycles at 0.71 and $0.15 \mathrm{~Hz}$. 

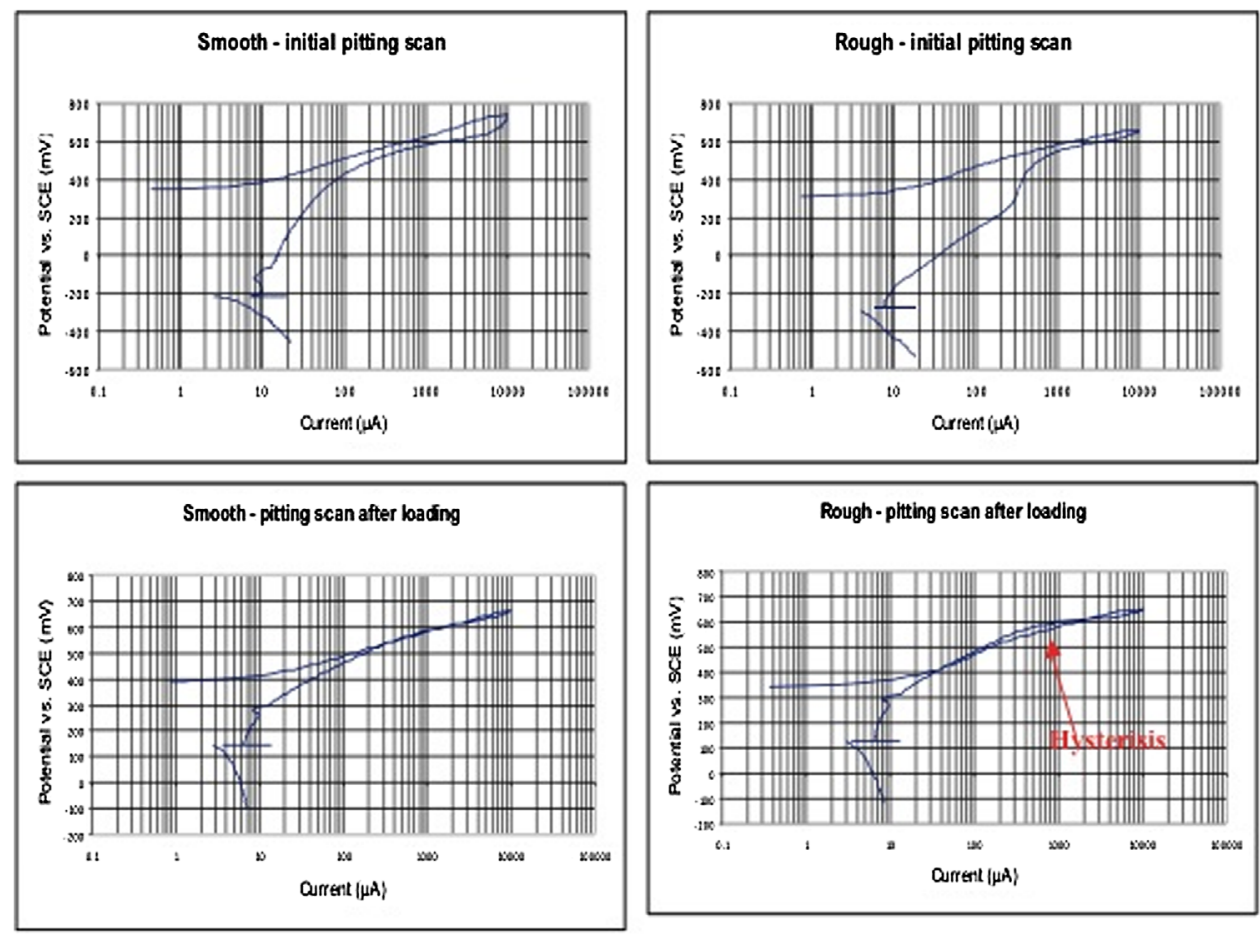

Figure 8. Pitting scans: rough versus smooth mini neck tapers pre- and post-loading.

material lost from the surface of the head. Dividing the trunnion using a slitting saw preserved morphological features associated with mechanically assisted corrosion, but did not allow a volumetric analysis of the material lost. The CoCrMo head is harder and is generally considered more wear resistant than the $\mathrm{Ti}$ alloy neck. Compared to Ti alloy, CoCrMo is more susceptible to galvanic corrosion, so the material loss is likely associated with corrosion rather than wear. However, the circumferential morphology of the CoCrMo surface after testing was found only in regions associated with high loading. The fact that the

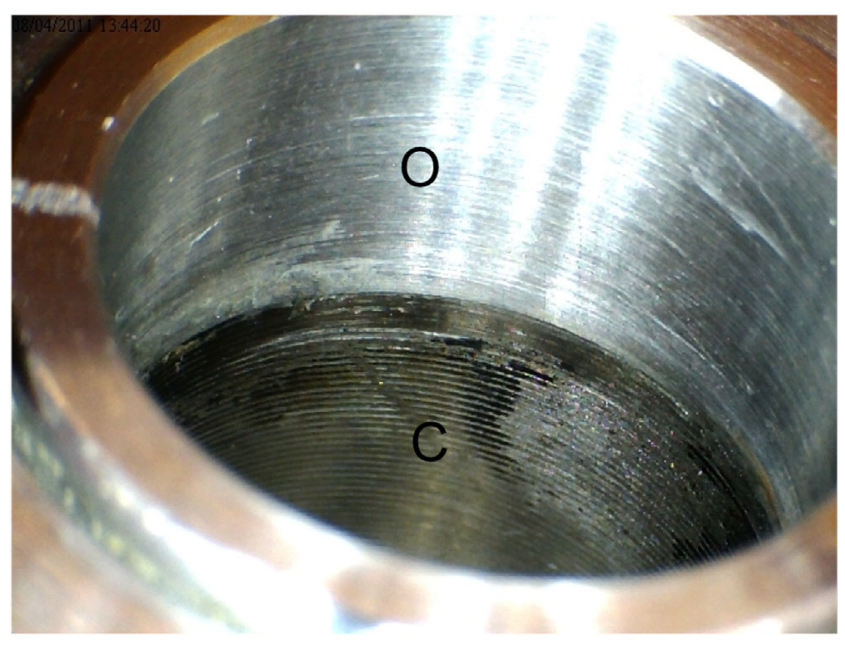

Figure 9. Photograph of a retrieved femoral head that shows the circumferential patterning (C) and the original machine marks $(\mathrm{O})$. This implant was retrieved after 18 months. morphology on the CoCrMo affected region is consistent with the machining marks on the Ti alloy surface suggests that this rough finish enhances crevice corrosion by allowing the ingress of fluid along the valleys. This is supported by the observation that the original machine marks were still evident in the affected region between the peaks created by the neck taper.

The greatest corrosion was seen at the interfaces where the highest bending movements were generated, suggesting that micromotion contributes to corrosion, as has been previously reported. ${ }^{17-19}$ Fretting and corrosion are observed together in most cases. However, in some instances, corrosion is observed without fretting, most likely because the signs of the initial fretting damage are obscured by progressive corrosion. $^{8}$ As fretting continues, the OCP decreases into the active-passive transition region, the $\mathrm{pH}$ inside the crevice decreases, and crevice corrosion is accelerated. This acidic crevice environment will then reach areas of the head where fretting scars were present, destroying the evidence of fretting. Recent in vitro studies showed that fretting initiated crevice corrosion in modular tapers can continue when fretting ceases, once the acidic crevice environment is established. ${ }^{10} \mathrm{In}$ our tests, crevice corrosion appears to be the overriding mechanism as substantiated from SEM examination of the corroded areas, which showed pitting, a characteristic of crevice corrosion.

The electrochemical tests supported the concept of fretting in our rough mini neck taper samples because of the cyclic nature in the potentiostatic cyclically loaded tests and current spikes in the potentiostatic 
tests. The fact that pitting was more evident on the mini neck tapers may be partly explained by the reduced contact area compared to that of the standard neck tapers. Forces may be concentrated and exceed the surface oxide fracture strains in the CoCrMo, leading to accelerated corrosion. Goldberg et al. ${ }^{8}$ showed the importance of neck stiffness on corrosion and concluded that larger diameter neck tapers have lower fretting corrosion rates. This may be due to reduced contact pressures resulting from increased moment arm effectively reducing the bending moment at the interface. In the mini neck tapers, the taper diameter was smaller and may explain the greater corrosion. Increasing contact area relative to the loading may reduce stresses and thus fretting corrosion. Rough surface finishes were developed for use with ceramic heads and then applied to MoM bearings. In view of our results, a rough finish may be inappropriate for large head MoM combinations where the torque may be higher on the taper.

In our electrochemical tests differences existed between rough and smooth neck tapers. There was a large decrease in the OCP in the rough compared to the smooth neck tapers, indicating that only a small amount of fretting occurred in the smooth neck taper. Further testing showed no noticeable fretting currents, implying minimal disruption to the oxide film. The tapers evaluated in this study had been through 10 million cycles, and this may have influenced the results. Gilbert et al. ${ }^{17}$ showed that fretting corrosion reactions decreased over a long-term test and suggested that corrosion debris may act like a boundary lubricant between the two surfaces. Fretting evidenced by potentiostatic tests was greater in tapers that were newly manufactured, compared with tapers that were previously cyclically loaded, suggesting that fretting is reduced with cyclic loading ${ }^{11}$ and that the interface has properly bedded in. With newly manufactured tapers, fretting current behaviors indicated less fretting with a taper that had a smooth finish. From our results it seems likely that a rough finish may be unsuitable for neck tapers.

In conclusion, we identified enhanced fretting corrosion at the modular taper junction associated with roughened surface finish and small neck tapers, underscoring the concern associated with the use of modular taper connections in orthopedic implants. Crevice corrosion was identified as the predominant mechanism, with evidence of pitting in all rough mini neck tapers. The greatest wear and corrosion was in the plane where the greatest bending moments were generated, implicating fretting as a mechanism. The rough mini neck tapers have a reduced surface area at the interface and ultimately bending forces are concentrated here.

\section{ACKNOWLEDGMENT}

This work was partly funded by Orthopaedic Research UK.

\section{REFERENCES}

1. Crowninshield RD, Maloney WJ, Wentz DH, et al. 2004. Biomecanics of large femoral heads: what they do and don't do. Clin Orthop 429:102-107.

2. Smith T, Berend K, Lombardi A Jr, et al. 2005. Metal-onmetal total hip arthroplasty with large heads may prevent early dislocation. Clin Orthop 44:137.

3. Langton DJ, Jameson SS, Joyce TJ, et al. 2008. The effect of component size and orientation on the concentrations of metal ions after resurfacing arthroplasty of the hip. J Bone Surg Br 90-B:1143-1151.

4. Haddad FS, Thakrar RR, Hart AJ, et al. 2011. Metal-on-metal bearings: the evidence so far. J Bone Surg Br 93:572-579.

5. National Joint Registry for England and Wales: 7th Annual Report September 2010. www.njrcentre.org.uk

6. MHRA. Medical device alert: accessed 24/5/2011. http:/ www.mhra.gov.uk/Publications/Safetywarnings/MedicalDeviceAlerts/CON093789

7. Vendittoli PA, Amzica T, Roy AG, et al. 2011. Metal Ion release with large-diameter metal-on-metal hip arthroplasty. J Arthroplasty 26:282-288.

8. Goldberg JR, Gilbert JL, Jacobs JJ, et al. 2002. A multicenter retrieval study of the taper interfaces of modular hip prostheses. Clin Orthop 401:149-161.

9. Kop AM, Swarts E. 2009. Corrosion of a hip stem with a modular neck taper junction: a retrieval study of 16 cases. J Arthroplasty 24:1019-1023.

10. Langton DJ, Jameson SS, Joyce TJ, et al. 2011. Accelerating failure rate of the ASR total hip replacement. J Bone Joint Surg Br 93:1011-1016.

11. Bolland BJ, Culliford DJ, Langton DJ, et al. 2011. High failure rates with a large-diameter hybrid metal-on-metal total hip replacement: clinical, radiological and retrieval analysis. J Bone Joint Surg Br 93:608-615.

12. Learmonth ID. 2000. Clinical implications of component modularity in total hip replacement. interfaces in total hip arthroplasty. London: Springer-Verlag; p 59-68.

13. Hozack WJ, Mesa JJ, Rothman RH. 1996. Head/neck modularity for total hip arthroplasty. Is it necessary? J Arthroplasty 11:397-400.

14. Krushell RJ, Burke DW, Harris WH. 1991. Range of motion in contemporary total hip arthroplasty. The impact of modular head-neck components. J Arthroplasty 6:97.

15. Chmell MJ, Rispler D, Poss R. 1995. The impact of modularity in total hip arthroplasty. Clin Orthop 319:77-84.

16. Barrack LR, Burke DW, Cook SD, et al. 1993. Complications related to modularity of total hip components. J Bone Joint Surg Br 75B:688-692.

17. Gilbert JL, Buckley CA, Jacobs JJ. 1993. In vivo corrosion of modular hip prosthesis components in mixed and similar metal combinations. The effect of crevice, stress, motion, and alloy coupling. J Biomed Mater Res 27:1533-1544.

18. Daxiong HE, Zhang Yinshun W. 2002. Fretting and galvanic corrosion behaviours and mechanisms of Co-Cr-Mo and Ti-6Al-4V alloys. Wear 249:883-891.

19. Collier JP, Surprenant VA, Jensen RE, et al. 1991. Corrosion at the interface of cobalt-alloy heads on Ti-alloy stems. Clin Orthop 271:305-312. 